Editorial

\title{
Audiology in the Time of the Coronavirus
}

J Am Acad Audiol 2020;31:309.

In these perilous and tragic times, when bad news is omnipresent and seemingly inexhaustible, know that we will be here for you when the battles have ended.
No disease will change that simple fact.

Our hearts are with you and with those you love.

The Editors
DOI https://doi.org/ 10.1055/s-0040-1712477. ISSN 1050-0545. 